\title{
Hydrodesulfurization of Heavy Naphtha by using NiMo Supported on Graphene
}

\author{
${ }^{1}$ Hameed Hussein Alwan and ${ }^{2}$ Hasan F. Makki \\ ${ }^{1}$ College of Engineering, University of Babylon, Hillah, Iraq \\ ${ }^{2}$ College of Engineering, University of Baghdad, Baghdad, Iraq
}

\begin{abstract}
In this study has been removed sulfur from heavy naphtha by hydrodesulfurization reaction HDS on catalyst consists NiMo supported on graphene, the experiments were done in fixed bed reactor contain catalyst bed. The experiments were designed by using Taguchi method. The design involved study of effect reaction temperature $523-598^{\circ} \mathrm{K}$, space velocity LHSV (3-6) $\mathrm{h}^{-1}$ and hydrogen pressure (1-1.3) MPa while $\mathrm{H}_{2} / \mathrm{oil}$ ratio was kept contestant at $50 \mathrm{~mL} / \mathrm{mL}$. Taguchi method help to results analysis in which the analysis exhibited general trend effect for controllable variables. A mathematical model was got for predicting sulfur content in final product by used Levenberg-Marquardt nonlinear regression.
\end{abstract}

Key words: Naphtha, catalyst, NiMo catalyst, graphene, hydrodesulfurization, reaction kinetics

\section{INTRODUCTION}

The big challenge in petroleum industrial is production fuel with minimum sulfur content because presence of sulfur causes sulfur oxides emission which make harmful risks on environment, corrosion of equipment take pace in containers, pipes, reactors and other metallic equipment. The presence of sulfur even in low concentration cause poising of valuable catalysts in downstream reactor, i.e., catalytic reforming unit.

Hydrodesulfurization reaction $\mathrm{HDS}$ is process consists a chemical conversion reaction for different types of petroleum fuel with hydrogen at elevated temperature and pressure in presence of suitable catalyst and the products of this reaction are corresponding hydrocarbon and hydrogen sulfide gas. Classical catalysts used for HDS process are $\mathrm{CoMo}$, NiMo and NiW supported on alumina, silica or silica-alumina. The presence of cobalt, molybdenum, nickel and tungsten in form of metal or metal oxides (McKetta Jr., 1992).

The production of high active and selectivity HDS catalyst is most important challenge in petroleum industries because there is some problem like high interaction between active compounds with support. Carbon used as catalyst support had been attracted many researchers via. its higher activity, lower coke formation and easy recovery from catalyst waste. Graphene is a mono layer for carbon atoms arranged in hexagonal honey comp structure and characterized with high surface area and high mechanical strength agent with thermal and chemical stability (Zeinab et al., 2016).
The present study is for investigation $\mathrm{NiMo} / \mathrm{G}$ catalyst activity for HDS reaction for heavy naphtha via. studying sulfur removal as a function for reaction temperature, space velocity and hydrogen pressure. The kinetics study was done to find the reaction order and reaction activation energy.

\section{MATERIALS AND METHODS}

Experimental: Heavy naphtha provided from Al-Najaf refinery with total sulfur content $755 \mathrm{ppm}$ and hydrogen with purity $99 \%$.

Catalyst: The graphene used was prepared from Iraqi date syrup by dehydration with concentration sulfuric acid in which graphene used as a support for nickel and molybdenum (Hussain et al., 2009). For loading these metals it was need to functionalized graphene surface by ultrasonic treatment in sulfuric and nitric acids mixture to form functional groups at defect sites on graphene sheets. Drying resulting graphene, loading metals by co-impregnation technique with solution of ammonium heptamolybdate (as molybdenum source) and cobalt nitrate (as nickel source) the total loaded represented as 4.65 and 14.43 wt. $\%$ for nickel and molybdenum, respectively as shown in Fig. 1 for EDS spectrum. Afterwards, the obtained compounds were dried at $110^{\circ} \mathrm{C}$ and calcinated at $400^{\circ} \mathrm{C}$. Finaly, the prepared catalyst was formulated by using $5 \mathrm{wt}$ \% PVA as a binder and formulated as extrudate. The prepared catalyst was activated by using of gas oil (contain $9000 \mathrm{ppm}$ total sulfur) as a sulfiding agent.

Corresponding Author: Hameed Hussein Alwan, College of Engineering, University of Babylon, Hillah, Iraq 


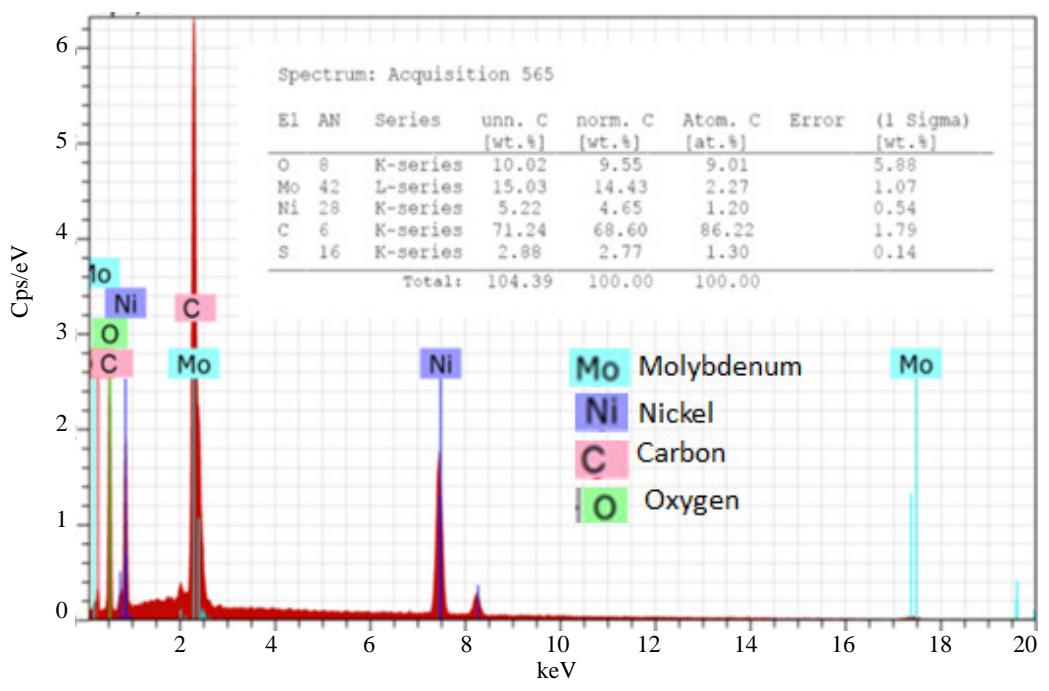

Fig. 1: EDS spectrum for $\mathrm{NiMo} / \mathrm{G}$ catalyst

Table 1: Controllable variables and their levels

\begin{tabular}{lllll}
\hline & Levels & & \\
& - & & & \\
Controllable variables & 1 & 2 & 3 & 4 \\
\hline Reaction temperature $\left({ }^{\circ} \mathrm{K}\right)$ & 523 & 548 & 573 & 598 \\
LHSV $\left(\mathrm{h}^{-1}\right)$ & 3 & 4 & 5 & 6 \\
Hydrogen pressure $(\mathrm{MPa})$ & 1 & 1.1 & 1.2 & 1.3 \\
\hline
\end{tabular}

Catalyst activity: The investigation for activity of prepared catalyst was done at hydrodesulfurization unit the catalyst bed was contained $56 \mathrm{~mL}$ of $\mathrm{NiMo} / \mathrm{G}$ catalyst and found in fixed bed reactor $(20 \mathrm{~mm}$ in diameter and $700 \mathrm{~mm}$ long), the effect of reaction temperature, LHSV and hydrogen pressure on HDS reaction for removing sulfur was studied by measuring total sulfur content with sulfur meter model RX-620SA/TANKA SCITIFIC.

Design of experiment: Design of experiment is a collection of experimental results and analysis with optimization these results, also, it can be used to find an mathematical expression for response as a function of independent (studied) variables.

Taguchi method is an experimental method in which it is a statistical technique used for improving quality of products. It was help to reduce the number of experiments (runs) that enough to cover the system range. Taguchi method was used for experiment design the HDS reaction activity, Table 1 shows the levels for studied variables ;reaction temperature, hydrogen pressure and space velocity which represented as controllable variables for final sulfur concentration in product, Table 2 shows Orthogonal Array $\mathrm{OA}=\mathrm{L}_{16}$ for application Taguchi method.

The purpose for HDS reaction is to reduce final sulfur concentration in product so the Signal-to Nose (S/N) used is smaller is better and calculated by following equation smaller is better:
Table 2: Taguchi's orthogonal array L16 with 3 variables and 4 levels each

\begin{tabular}{lcccccc} 
& \multicolumn{3}{l}{ Code values } & \multicolumn{3}{l}{ Real values } \\
Experiment & - & ----- & - & \\
1 & A & B & C & T( $\left.{ }^{2} \mathrm{~K}\right)$ & LHSV $\left(\mathrm{h}^{-1}\right)$ & P (MPa) \\
\hline 2 & 1 & 1 & 1 & 523 & 3 & 1.0 \\
3 & 1 & 2 & 2 & 523 & 4 & 1.1 \\
4 & 1 & 3 & 3 & 523 & 5 & 1.2 \\
5 & 1 & 4 & 4 & 523 & 6 & 1.3 \\
6 & 2 & 1 & 2 & 548 & 3 & 1.1 \\
7 & 2 & 2 & 1 & 548 & 4 & 1.0 \\
8 & 2 & 3 & 4 & 548 & 5 & 1.3 \\
9 & 2 & 4 & 3 & 548 & 6 & 1.2 \\
10 & 3 & 1 & 3 & 573 & 3 & 1.2 \\
11 & 3 & 2 & 4 & 573 & 4 & 1.3 \\
12 & 3 & 3 & 1 & 573 & 5 & 1.0 \\
13 & 3 & 4 & 2 & 573 & 6 & 1.1 \\
14 & 4 & 1 & 4 & 598 & 3 & 1.3 \\
15 & 4 & 2 & 3 & 598 & 4 & 1.2 \\
16 & 4 & 3 & 2 & 598 & 5 & 1.1 \\
\hline
\end{tabular}

$$
\mathrm{SN}_{\mathrm{s}}=-10 \log \left(\frac{\sum_{\mathrm{i}=1}^{\mathrm{n}} \mathrm{y}_{\mathrm{i}}^{2}}{\mathrm{n}}\right)
$$

Table 3 measured results according to Taguchi method experimental design for naphtha HDS reaction.

Statistical analysis: The experimental data was analyzed with statistical method by used SPSS Software in which statistical method dealing with effect of varying of several variables at the same time or in other word relate the response (final sulfur content in product) with controllable variables (reaction temperature, LHSV and hydrogen pressure). Effect of reaction temperature, LHSV and hydrogen pressure on final sulfur content in product from HDS reaction were studied by assuming that system obey second order polynomial: 


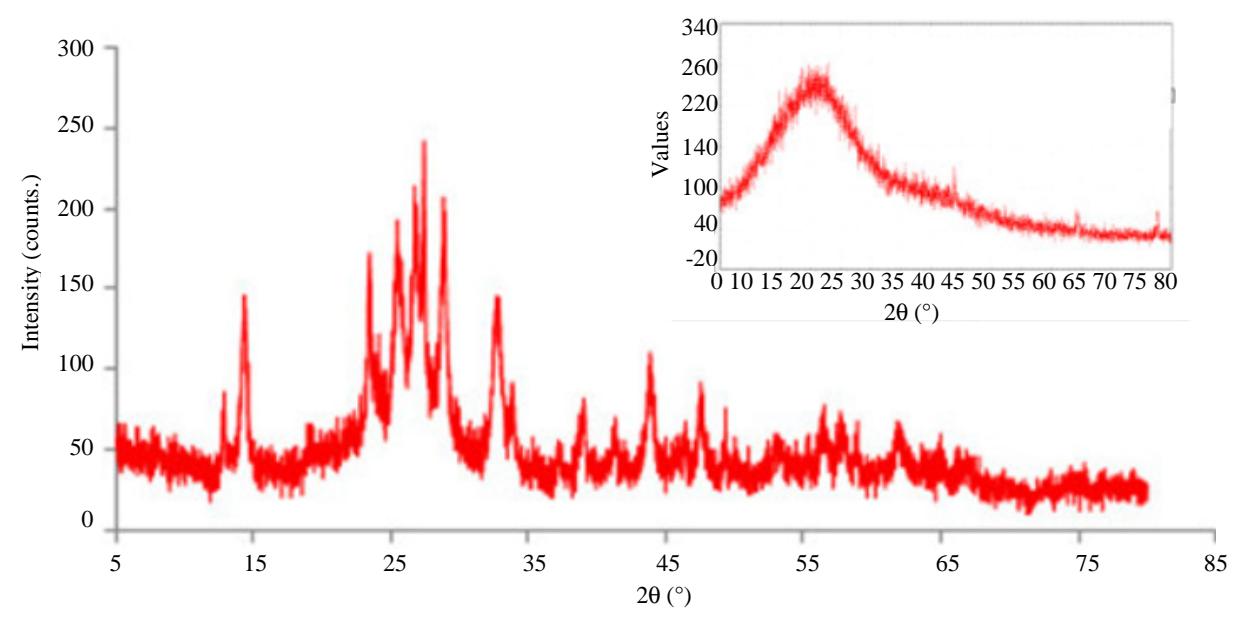

Fig. 2: XRD pattern for $\mathrm{NiMo/G}$ catalyst. Inset $\mathrm{XRD}$ pattern for prepared graphene

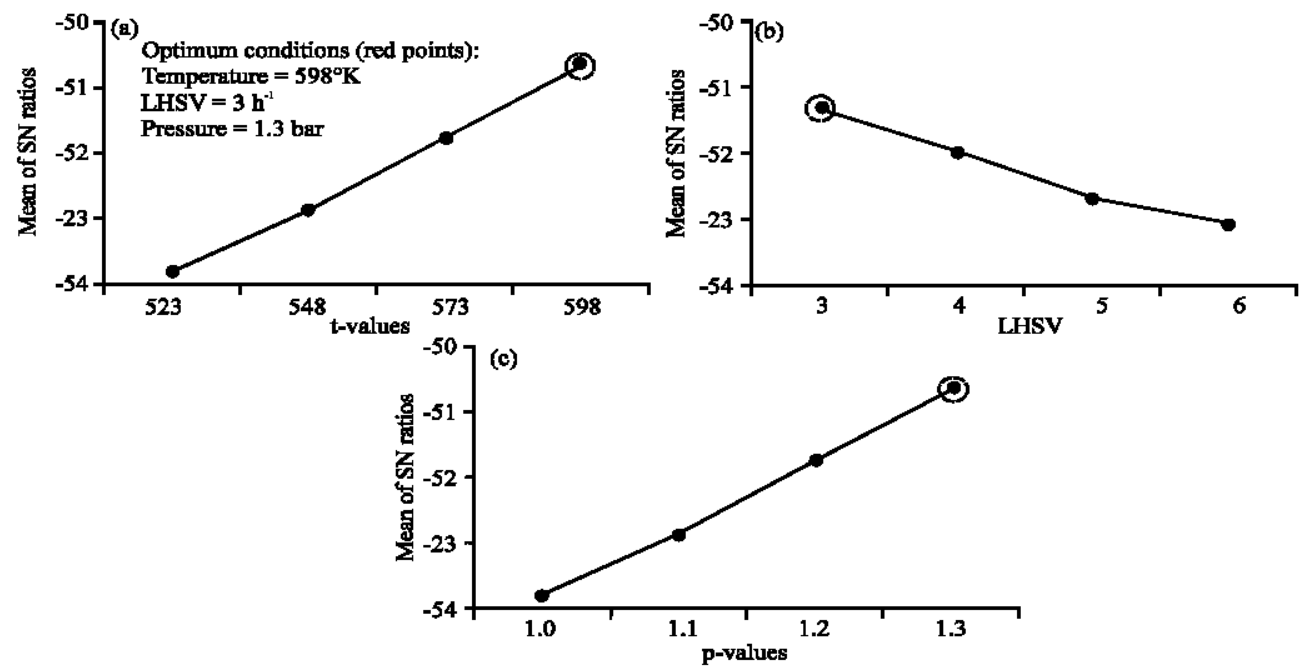

Fig. 3: The general trend rend for reaction temperature, LHSV and pressure on sulfur content in final product for reaction at $\mathrm{NiMo} / \mathrm{G}$ catalyst

\begin{tabular}{|c|c|c|c|c|c|c|}
\hline \multirow[b]{3}{*}{$\underline{\text { Run }}$} & \multirow{2}{*}{\multicolumn{3}{|c|}{ Code values }} & \multicolumn{3}{|c|}{ Sulfur concentration (ppm) } \\
\hline & & & & \multicolumn{3}{|c|}{$\mathrm{NiMo} / \mathrm{G}$ catalyst } \\
\hline & $\mathrm{A}$ & $\mathrm{B}$ & $\mathrm{C}$ & $1^{\text {st }}$ trial & 2nd trail & Average \\
\hline 1 & 1 & 1 & 1 & 540 & 548 & 544 \\
\hline 2 & 1 & 2 & 2 & 519 & 513 & 516 \\
\hline 3 & 1 & 3 & 3 & 483 & 485 & 484 \\
\hline 4 & 1 & 4 & 4 & 452 & 448 & 450 \\
\hline 5 & 2 & 1 & 2 & 413 & 421 & 417 \\
\hline 6 & 2 & 2 & 1 & 517 & 515 & 516 \\
\hline 7 & 2 & 3 & 4 & 358 & 360 & 359 \\
\hline 8 & 2 & 4 & 3 & 441 & 439 & 440 \\
\hline 9 & 3 & 1 & 3 & 299 & 287 & 293 \\
\hline 10 & 3 & 2 & 4 & 271 & 273 & 272 \\
\hline 11 & 3 & 3 & 1 & 487 & 483 & 485 \\
\hline 12 & 3 & 4 & 2 & 423 & 457 & 440 \\
\hline 13 & 4 & 1 & 4 & 211 & 175 & 193 \\
\hline 14 & 4 & 2 & 3 & 285 & 259 & 272 \\
\hline 15 & 4 & 3 & 2 & 356 & 366 & 361 \\
\hline$\underline{16}$ & 4 & 4 & 1 & 455 & 449 & 452 \\
\hline
\end{tabular}

$$
\begin{aligned}
& \mathrm{S}_{\mathrm{f}}=\mathrm{a}_{0}+\mathrm{a}_{1} \mathrm{~T}^{2}+\mathrm{a}_{2} \mathrm{LHSV}^{2}+\mathrm{a}_{2} \mathrm{P}^{2}+\mathrm{a}_{4} \mathrm{~T}+\mathrm{a}_{5} \mathrm{LHSV}+ \\
& \mathrm{a}_{6} \mathrm{P}+\mathrm{a}_{7} \mathrm{~T}^{*} \mathrm{LHSV}+\mathrm{a}_{8} \mathrm{~T}^{*} \mathrm{P}+\mathrm{a}_{\mathrm{p}} \mathrm{LHSV} \mathrm{P}^{*} \mathrm{P}
\end{aligned}
$$

The mathematical expression for predicting sulfur content in final product was got as multiple regressions with SPSS Software in which the mathematical expression for second order polynomial is (Fig. 2 and 3):

$$
\begin{aligned}
& \mathrm{S}_{\mathrm{f}}=4139.96+0.005 \mathrm{~T}^{2}-2.25 \mathrm{LHSV}^{2}+300.0 \mathrm{P}^{2}- \\
& 7.982 \mathrm{~T}+111.14 \mathrm{LHSV}-1339.922 \mathrm{P}-0.072 \mathrm{~T} \\
& { }^{*} \mathrm{LHSV}+0.209 \mathrm{~T} * \mathrm{P}-19.318 \mathrm{LHSV} * \mathrm{P}
\end{aligned}
$$

\section{RESULTS AND DISCUSSION}

Effect of controlled variables on sulfur removal: Sulfur removal percentage can be calculated by: 


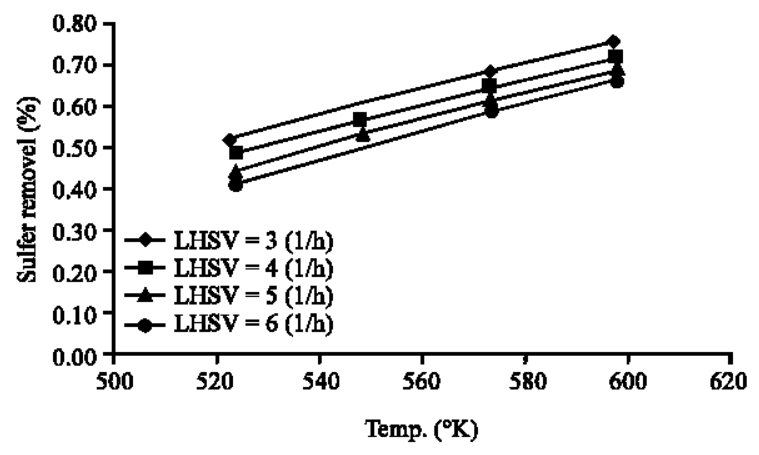

Fig. 4: Interaction effect for temperature effect and LHSV on removal of sulfur from naphtha by using $\mathrm{NiMo} / \mathrm{G}$ catalyst at hydrogen pressure $1.3 \mathrm{MPa}$

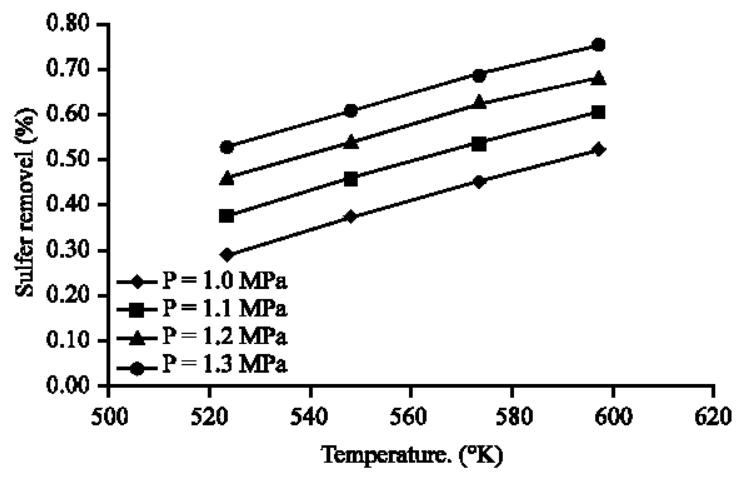

Fig. 5: Interaction effect for temperature effect and hydrogen pressure on removal of sulfur from naphtha by using NiMo/G catalyst at LHSV $=3 \mathrm{~h}^{-1}$

$$
\mathrm{S} \%=\frac{\mathrm{S}_{\mathrm{f}}-\mathrm{S}_{0}}{\mathrm{~S}_{0}}
$$

Temperature effect on sulfur removal: Figure 4 shows the reaction temperature effect on sulfur removal for HDS reaction at different value for LHSV while Fig. 5 shows the effect at different values for hydrogen pressure, it can be noted that increasing in reaction temperature the sulfur removal percentage was increasing and this is because temperature increasing lead to raise in internal molecular motion which lead to increasing reaction as reported by many researchers (Lan et al., 2009; Muhammed, 2017).

Space velocity effect on sulfur removal: The effect of LHSV on sulfur removal was shown in Fig. 6 with increasing LHSV at the same temperature the sulfur removal was decreasing, i.e., temperature $598^{\circ} \mathrm{K}$ the sulfur removal reduced from $75 \%$ at LHSV $3 \mathrm{hr}^{-1}$ to $66 \%$ at LHSV $6 \mathrm{hr}^{-1}$ and this is increasing in LHSV causes decreasing in contact time between reactants and vice versa and this is agree with (Muhammed, 2017).

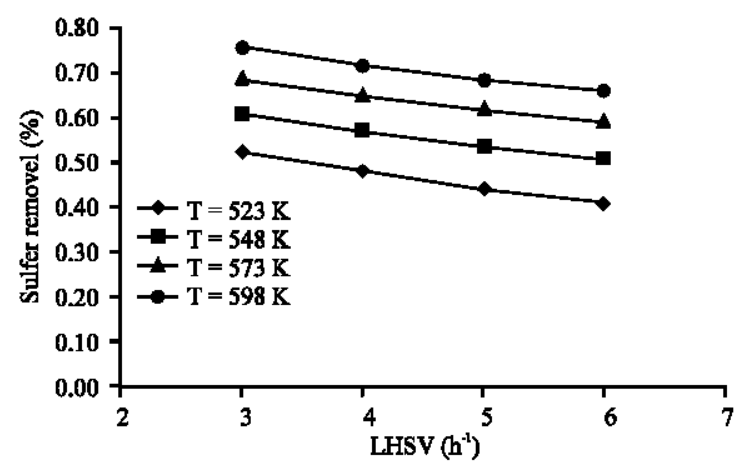

Fig. 6: Interaction effect for LHSV and temperature on removal of sulfur from naphtha by using $\mathrm{NiMo} / \mathrm{G}$ catalyst at pressure $=1.3 \mathrm{MPa}$

Effect of hydrogen pressure: Increasing in hydrogen pressure lead to increasing conversion of reaction and this may be because coke formation reduction on catalyst surface (Kundu et al, 2003). The increasing in sulfur removal with pressure increase due to increasing in pressure cause hydrogenolysis of sulfur organic compounds as Sayed reported (Liu et al., 2008). Changlong Yin suggests that HDS product was very sensitive to pressure of reaction, especially at low pressure near $1 \mathrm{MPa}$ in which caused cracking of naphtha at catalyst surface, thus increasing in pressure will enhanced HDS product (Yin et al., 2003).

HDS reaction kinetics: There many parameters need to estimate during kinetics studying and for that it was used Levenberg-Marquardt method for fitting experimental data. Method of Levenberg-Marquardt algorithm is standard technique to solve nonlinear problems by fitting function parameters with set of experimental data points by reduce sum of error squares between suggested relation and experimental data. Levenberg-Marquardt method is a combination of two minimization method; Gauss-Newton method and gradient descent method (Urych, 2014) (Fig. 7).

Assume that naphtha HDS reaction is obeyed nth order with respect to sulfur concentration and interference hydrogen pressure effect on reaction:

$$
\frac{\mathrm{dC}}{\mathrm{dt}}=-\mathrm{kC}^{\mathrm{n}} \mathrm{P}_{\mathrm{H}_{2}}^{\mathrm{a}}
$$

By integration we get:

$$
\mathrm{C}_{\mathrm{f}}^{1-\mathrm{n}}-\mathrm{C}_{0}^{1-\mathrm{n}}=(\mathrm{n}-1) \mathrm{kP}_{\mathrm{H}_{2}}^{\mathrm{a}} \mathrm{t}
$$

Time in Eq. 6 can be converted in term of space velocity (LHSV) by introduce index b: 


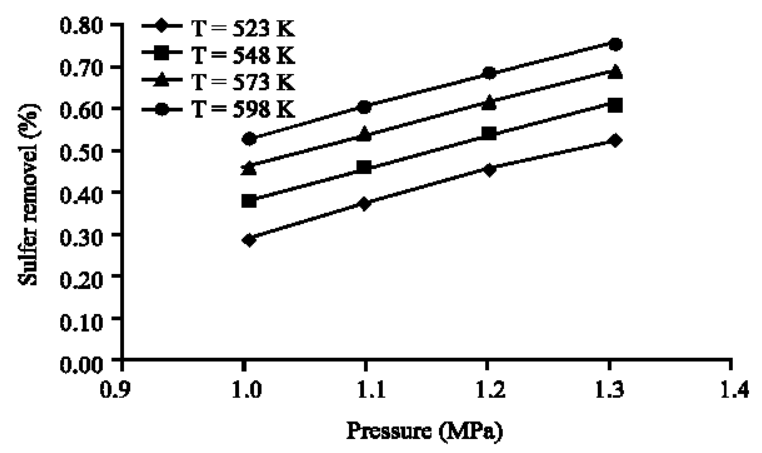

Fig. 7: Pressure effect on removal of sulfur from naphtha by using $\mathrm{NiMo} / \mathrm{G}$ catalyst at $\mathrm{LHSV}=3 \mathrm{~h}^{-1}$

$$
\mathrm{C}_{\mathrm{f}}^{-\mathrm{n}}-\mathrm{C}_{0}^{1-\mathrm{n}}=(\mathrm{n}-1) \mathrm{kP}_{\mathrm{H}_{2}}^{\mathrm{a}} \mathrm{t}(\mathrm{LHSV})^{\mathrm{b}}
$$

Reaction rate constant can be expressed according Arrhenius Eq. 8:

$$
\mathrm{C}_{\mathrm{f}}^{1-\mathrm{n}}-\mathrm{C}_{0}^{1-\mathrm{n}}=(\mathrm{n}-1) \mathrm{k}_{0} \mathrm{P}_{\mathrm{H}_{2}}^{\mathrm{a}} \mathrm{t}(\text { LHSV })^{\mathrm{b}} \exp \left(-\frac{\mathrm{E}}{\mathrm{RT}}\right)
$$

Rearrange Eq. 8:

$$
\mathrm{C}_{\mathrm{f}}=\left[(\mathrm{n}-1) \mathrm{k}_{\mathrm{O}} \mathrm{P}_{\mathrm{H}_{2}}^{\mathrm{a}}(\mathrm{LHSV})^{\mathrm{b}} \exp \left(-\frac{\mathrm{E}}{\mathrm{RT}}\right)+\mathrm{C}_{0}^{1-\mathrm{n}}\right]\left(\frac{1}{1-\mathrm{n}}\right)(9)
$$

Equation 9 relates sulfur concentration with operation condition (initial sulfur concentration, hydrogen pressure, reaction temperature and space velocity) and contains kinetics parameters (reaction order, activation energy and pre-exponential factor of Arrhenius equation). To estimate kinetics parameters Levenberg-Marquardt method was used by fitting experimental data with nonlinear regression with aid of SPSS Software. The kinetics parameters were found as follow:

$$
\begin{aligned}
& \mathrm{E}=35,159 \mathrm{KJ} / \mathrm{mol} ., \mathrm{n}=2.035, \\
& \mathrm{a}=3,904, \mathrm{~b}=-0.0667 \text { and } \mathrm{k} 0=2.772
\end{aligned}
$$

The kinetics expression or Eq. 9 can be written as:

$$
\mathrm{C}_{\mathrm{f}}=\left[\begin{array}{l}
2.87 \mathrm{P}_{\mathrm{H}_{2}}^{3.906}(\mathrm{LHSV})^{-0.667} \exp \\
\left(-\frac{35159}{\mathrm{RT}}\right)+\mathrm{C}_{0}^{-1.305}
\end{array}\right]^{-0.966}
$$

\section{CONCLUSION}

$\mathrm{NiMo/graphene} \mathrm{was} \mathrm{used} \mathrm{as} \mathrm{a} \mathrm{catalyst} \mathrm{for}$ hydrodesulfurization process with good effect for sulfur removing from heavy naphtha. According to Taguchi method heavy naphtha HDS reaction shows the general trend increasing sulfur removal with temperature and pressure while decrease with increasing in LHSV. The system for HDS reaction can be described by second order (quadratic) model and showing high ability for prediction sulfur content in final product.

Power law model was used to build a kinetics model for heavy naphtha HDS reaction by fitting experimental data with Levenberg-Marquardt nonlinear regression which give $\mathrm{R}^{2}=0.997$ and the kinetics parameters are: $\mathrm{E}=$ $35,159 \mathrm{~kJ} / \mathrm{mol}, \mathrm{n}=2.035, \mathrm{a}=3,904, \mathrm{~b}=-0.0667$ and $\mathrm{k} 0=$ 2.772 .

\section{REFERENCES}

Hussain, S.T., F. Zia and M. Mazhar, 2009. Modified nano supported catalyst for selective catalytic hydrogenation of edible oils. Eur. Food Res. Technol., 228: 799-806.

Kundu, A., K.D.P. Nigam, A.M. Duquenne and H. Delmas, 2003. Recent developments on hydroprocessing recations. Rev. Chem. Eng., 19: 531-605.

Lan, X., C. Xu, G. Wang and J. Gao, 2009. Reaction performance of FCC slurry catalytic cracking. Catal. Today., 140: 174-178.

Liu, S., B. Wang, B. Cui and L. Sun, 2008. Deep desulfurization of diesel oil oxidized by $\mathrm{Fe}$ (VI) system. Fuel., 87: 422-428.

McKetta Jr., J.J., 1992. Petroleum Processing Handbook. CRC Press Publisher, Boca Raton, Florida, USA., Pages: 759 .

Muhammad, S., 2017. Synthesis and characterization of $\mathrm{CoMo} / \mathrm{a}$ alumina and $\mathrm{NiMo} / \mathrm{a}$ alumina for hydrodesulfurization of gas oil. Ph.D Thesis, University of Baghdad, Baghdad, Iraq.

Urych, B., 2014. Determination of kinetic parameters of coal pyrolysis to simulate the process of Underground Coal Gasification (UCG). J. Sustainable Min., 13: 3-9.

Yin, C., R. Zhao and C. Liu, 2003. Hydrodesul furization of fluid catalytic cracked naphtha over bifunctional Ni-Mo/HZSM-5 catalyst. Prepr. Pap. American Chem. Soc. Div. Fuel Chem., 48: 662664.

Zeinab, H., M. Kazemeini, A. Rashidi and M. Bazmi, 2016. Graphene based catalysts for deep hydrodesulfurization of naphtha and diesel fuels: A physiochemical study. Fuel., 165: 468476. 